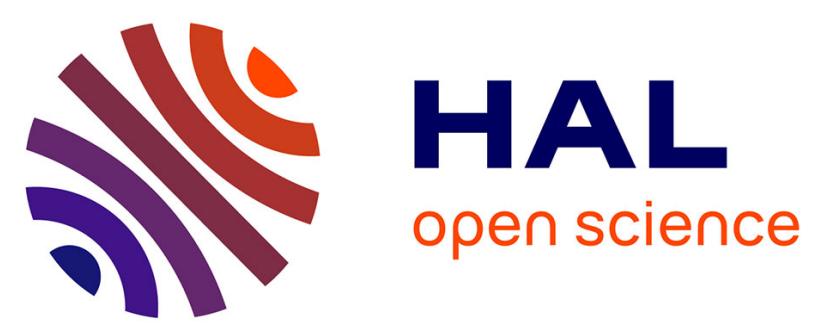

\title{
Government expenditure, external and domestic public debt, and economic growth
}

Cuong Le Van, van Phu Nguyen, Amélie Barbier-Gauchard, Duc-Anh Le

\section{To cite this version:}

Cuong Le Van, van Phu Nguyen, Amélie Barbier-Gauchard, Duc-Anh Le. Government expenditure, external and domestic public debt, and economic growth. Journal of Public Economic Theory, 2019, 21 (1), pp.116-134. 10.1111/jpet.12324 . hal-02093378

\section{HAL Id: hal-02093378 \\ https://hal.science/hal-02093378}

Submitted on 9 Sep 2021

HAL is a multi-disciplinary open access archive for the deposit and dissemination of scientific research documents, whether they are published or not. The documents may come from teaching and research institutions in France or abroad, or from public or private research centers.
L'archive ouverte pluridisciplinaire HAL, est destinée au dépôt et à la diffusion de documents scientifiques de niveau recherche, publiés ou non, émanant des établissements d'enseignement et de recherche français ou étrangers, des laboratoires publics ou privés. 


\title{
Government expenditure, external and domestic public debt, and
}

\author{
economic growth*
}

\author{
Cuong LE VAN ${ }^{\dagger}$ Phu NGUYEN-VAN ${ }^{\ddagger}$ Amélie BARBIER-GAUCHARD ${ }^{\S}$ \\ Duc-Anh LE
}

\begin{abstract}
This paper analyzes the relationship between government expenditure, tax on returns to assets, public debt, and growth in an endogenous growth model. Public debt is composed of two components, domestic debt and external debt. We show conditions for existence, uniqueness, and multiplicity of the steady states. More precisely, existence of steady state requires a sufficiently high productivity and a sufficiently low tax on returns to assets. We also provide the effects of an increase in the tax rate on returns to assets on the steady state. In particular, the relation between public spending and the tax rate has a bell shape. Domestic debt unambiguously increases with tax whereas external debt displays an inverted U-shaped curve. A high tax rate leads to a reallocation of public debt in favor of domestic debt (to the detriment of external debt). The effect of taxation on consumption (and production) also displays a nonlinear pattern when the output elasticity of capital is lower than unity (the effect is monotonously increasing if this elasticity is unity). We also derive the conditions under which a tax increase can boost or reduce the balanced growth rate.
\end{abstract}

Keywords: Tax on returns to assets; Public expenditure; Domestic debt; External debt; Growth JEL Classification: H50; H63; O40

\footnotetext{
${ }^{*}$ We are grateful to the editor, an associate editor, three anonymous reviewers of the journal and participants of AFSE 2015, PET 2015, and several seminars for their very helpful comments that allowed us to considerably improve the content of the paper. The usual caveat applies.

${ }^{\dagger}$ IPAG, CNRS, PSE, APD, TIMAS. Cuong Le Van is partially funded by Vietnam National Foundation for Science and Technology Development (NAFOSTED) under grant number 502.01-2017.12.

${ }^{\ddagger}$ BETA, CNRS, INRA and Université de Strasbourg \& TIMAS, Thang Long University. Corresponding author: P. Nguyen-Van, BETA, CNRS, INRA \& Université de Strasbourg, 61 avenue de la Forêt Noire, F-67000 Strasbourg, France; Phone: +33-368 552 039; E-mail: nguyen-van@unistra.fr

$\S$ BETA, CNRS, INRA and Université de Strasbourg

ॠBETA, CNRS, INRA and Université de Strasbourg
} 


\section{Introduction}

The impact of public investment on economic growth and the financing modalities are two major questions discussed by academics and have been reflected in public debate. This is particularly true for the OECD countries but also for emerging countries in recent years. Our paper contributes to this discussion, based on existing literature on these issues. Regarding public investment, since the seminal works of Aschauer (1989) and Barro (1990), a very abundant literature developed to assess its impact on growth. ${ }^{1}$ In this debate, the nature of public expenditure plays a major role (productive or unproductive, capital, education or health, infrastructure, social services, etc.).

The issue of financing public investment has long divided economists. This question has emerged as a crucial factor to consider when assessing the macroeconomic impact of public investment. Omitting the financing modalities of public investment will bias the analysis. We must also consider the budget constraint of public decision makers. The final impact on activity differs significantly depending on whether public investment is financed by public debt (in this case, the cost of financing is borne by future generations) or by taxation (in this situation, the financial resources of the economic agents are immediately and directly affected). A very abundant literature now exists on this issue.

Regarding the impact of taxes on growth, there are many works that differ in the type of taxes considered and in the methodology used. ${ }^{2}$ The debate focuses on the impact on growth of distorting taxation (taxes on income and profits, social security contributions, taxes on assets, etc.) and nondistorting taxes (VAT, etc.), and on the different effets of personal income tax rate versus corporate income tax. No consensus seems to emerge from this work.

Concerning the impact of public debt, we can also note a great diversity of works. These studies focuses on the relevance of this particular kind of ressources to finance public investment. ${ }^{3}$ Most of existing studies on the relationship between public debt and growth consider public debt as a domestic debt (see, e.g., Bohn 1998, Greiner 2007, and Checherita and Rother 2010). Nevertheless, in such context, public debt composition matters as highlighted by the seminal paper of Diamond

\footnotetext{
${ }^{1}$ See, for instance, Devarajan et al. (1996), Devarajan et al. (1996), Mundle (1999), Glomm and Ravikumar (1997), Gupta et al. (2005) or, more recently, Felice (2016).

${ }^{2}$ See, for example Futagami et al. (1993), Mullen and Williams (1994), Kneller et al. (1999) or Lee et al. (1997).

${ }^{3}$ See notably Greiner (2007), Reinhart and Rogoff (2010), Checherita and Rother (2010) or, more recently, Herndon et al. (2014) or Bom and Ligthart (2014).
} 
(1965). In the same vein, Turnovsky (1996), Calvo (1997), Calvo and Reinhart (2002) or Drazen (2000) focused on public debt management, risk default and credibility in economic policy. More recently, Dell'Erba et al. (2013) studied the relationship between sovereign spreads and the interaction between debt composition and debt levels in advanced and emerging market countries (see also Panizza and Presbitero, 2014). Ferreira de Mendonça and Rangel Machado (2014) offered a contribution to the literature concerning the management of the public debt in emerging economies. A novelty in this article is the introduction of a fiscal credibility index based on the market's expectations in regard to the public debt-GDP ratio. Clements et al. (2003) investigated the relationship between external debt, public investment, and growth in low-income countries and stated that high levels of public debt can depress economic growth in low-income countries and threshold levels of external debt was estimated around 50\% of GDP. In Futagami et al. (2008), government has a target level of government debt relative to the size of the economy. They showed that two steady states can emerge. One is associated with high growth and the other with low growth. It is also shown that whether the government uses income taxes or government bonds makes the results differ significantly. According to Ejigayehu (2013), Zaman and Arslan (2014), and Soydan and Bedir (2015), the empirical results generally reveal that the accumulation of external debt is associated with an increase in economic growth up to an optimal level, and that an additional increase of external indebtedness beyond the level inversely contributes to the economy. In other words, there exists a threshold above which a too high level of external debt has a negative effect on growth.

Recently, several developing and emerging countries adopted aggressive policies aimed at substituting external public debt with domestically issued debt (Panizza 2008, Presbitero 2012). Nevertheless, external debt continue to play an important role in financing public debt in these countries. As underlined by Panizza (2008) describing recent trends in the composition of public debt in developing countries, public debt corresponds to around 64\% of GDP in 2005 for all developing countries (40\% in external debt and $23 \%$ in domestic debt). For East Asia and Pacific countries (EAP), total public debt corresponds to 50\% of GDP in 2005 (35\% in external debt and 15\% in domestic debt). Although many existing studies assess the impact of the financing modalities of public investment, few of them consider different modalities simultaneously. Our paper proposes to fill this gap by analyzing the impact on growth of public investment and its financing instruments (external public 
debt, domestic public debt, and taxes). We focus on the government's trade-off in terms of these financing instruments. We are interested in the impact of this trade-off on the economic performance of a small economy in a dynamic perspective.

In this paper, we consider a neoclassical endogenous growth model and investigate the interaction between public investment, tax, public debt and growth. In order to isolate the role of taxes, we assume that tax on returns to assets is the only kind of tax in the economy. The originality of this paper resides in the consideration of two kinds of public debt simultaneously: domestic debt and external debt. Our economy comprises three sectors: namely government, firms, and consumers. We assume that the production of the final good depends on the stock of private capital but also on government spending. In other words, public investment had a positive impact on firm productivity. In this framework, we study the balanced growth path (BGP) of the model and focus on the impact of the tax rate on returns to private assets on the macroeconomic equilibrium. We show the conditions for existence, uniqueness, multiplicity and non existence of the BGP. The paper makes several interesting results. In particular, a nontrivial or positive (one or multiple) steady state can exist only if the productivity is large enough and the tax rate is not so high; otherwise, there is no positive BGP for the economy. We provide the effects of an increase in the tax rate on returns to assets on the steady state. More precisely, the relation between public spending and the tax rate has a bell shape, similar to the Laffer curve. Domestic debt unambiguously increases with tax whereas external debt displays an inverted U-shaped curve. A high tax rate leads to a reallocation of public debt in favor of domestic debt (to the detriment of external debt), supporting the recent policy observed in several countries where external public debt is substituted by its domestic counterpart. The effect of taxation on consumption (and production) also displays a nonlinear pattern when the output elasticity of capital is lower than unity (the effect is monotonously increasing if this elasticity is unity). We also derive the conditions under which a tax increase can boost or reduce the balanced growth rate. In particular, an increase in the tax rate is harmful to growth if it reduces public spending (i.e. when $\tau$ is sufficiently high). Tax can enhance growth if it rises public spending when the latter is low enough and/or the output elasticity of public spending is sufficiently large.

The remaining of the paper is organized as follows. The theoretical model, based on Barro (1990) and Greiner (2007), is introduced in Section 2. Section 3 presents the equilibrium of the model while 
Section 4 characterizes the conditions for existence, uniqueness, multiplicity, and non existence of the balanced growth path (BGP). Section 5 discusses the results, in particular the effects of tax on returns to assets on the steady state. The last section summarizes the main contributions of the study and gives some perspectives for further research.

\section{Model}

The growth model presented in this section is based on the models developed by Barro (1990) and Greiner (2007). Our economy comprises three sectors, namely firms, consumers, and government.

\section{$2.1 \quad$ Firms}

We assume that the production of the final good depends on the stock of private capital $K$ and government spending $G$ :

$$
Y_{t}=F\left(K_{t}, G_{t}\right)=H K_{t}^{\alpha} G_{t}^{1-\alpha}
$$

where $0<\alpha<1$ is output elasticity with respect to capital (and $1-\alpha$ is the elasticity corresponding to public spending), $H$ is total factor productivity or technological level. The production function $F$ is strictly increasing in both variables, strictly concave in $K . G$ may be considered as a positive externality for the production. As our purpose is to underly the public sector (public spending and public debt), we adopte this Barro's (1990) production function with constant return to scale and without labor input. The absence of labor input also helps simplify the analysis. The profit is given by $\pi_{t}=F\left(K_{t}, G_{t}\right)-r_{t}^{K} K_{t}\left(r_{t}^{K}\right.$ is the interest rate of capital). The first-order condition (FOC) for profit maximization is

$$
F_{K}\left(K_{t}, G_{t}\right) \equiv \frac{\partial F}{\partial K}=r_{t}^{K}
$$

By substituting equation (1) into equation (2), the interest rate of capital can be written as

$$
r_{t}^{K}=\alpha H K_{t}^{\alpha-1} G_{t}^{1-\alpha}=\alpha H\left(\frac{G_{t}}{K_{t}}\right)^{1-\alpha}
$$

or, equivalently,

$$
r_{t}^{K}=\alpha H g_{t}^{1-\alpha}
$$


where $g_{t} \equiv G_{t} / K_{t}$. Equation (4) implies that interest rate of private capital is determined by total factor productivity, output elasticity with respect to public spending, and the ratio of government expenditure and private capital.

\subsection{Consumers}

We assume that the representative consumer's instantaneous utility function is $U\left(C_{t}\right)=\ln C_{t}$ where $C_{t}$ is her consumption at period $t$. The representative consumer chooses her consumption, her stock of assets, and her government bonds (or domestic public debt) to maximize her inter-temporal utility $\sum_{t=0}^{+\infty} \beta^{t} U\left(C_{t}\right)$, where $\beta>0$ is the discount rate, under the budget constraint

$$
C_{t}+A_{t+1}+D_{t+1} \leq\left[r_{t}^{A}\left(1-\tau_{t}\right)+1\right] A_{t}+\left(r_{t}^{D}+1\right) D_{t}+\pi_{t}
$$

and positivity constraints $C_{t} \geq 0$ and $A_{t} \geq 0, \forall t$. Note that $C_{t}, A_{t}, D_{t}$, and $\pi_{t}$ are respectively consumption, private assets, domestic debt hold by the consumer, and the profit she receives as the firm owner. Interest rates $r_{t}^{A}$ and $r_{t}^{D}$ correspond to private assets and government bonds, respectively. The consumer has to pay a tax on returns to assets at the rate $\tau_{t}{ }^{4}$

The Lagrangian is

$$
L=\sum_{t=0}^{\infty} \beta^{t} U\left(C_{t}\right)-\sum_{t=0}^{\infty} \lambda_{t}\left\{\left[r_{t}^{A}\left(1-\tau_{t}\right)+1\right] A_{t}+\left(r_{t}^{D}+1\right) D_{t}+\pi_{t}-C_{t}-A_{t+1}-D_{t+1}\right\}+\sum_{t=1}^{\infty} \mu_{t} A_{t} .
$$

The FOCs are given as follows, $\forall t$,

$$
\begin{aligned}
\beta^{t} U^{\prime}\left(C_{t}\right)+\lambda_{t} & =0, \\
\lambda_{t}\left[\left(1+r_{t}^{A}\left(1-\tau_{t}\right)\right]-\lambda_{t-1}-\mu_{t}\right. & =0, \\
\lambda_{t}\left(1+r_{t}^{D}\right)-\lambda_{t-1} & =0, \\
\mu_{t} A_{t} & =0 .
\end{aligned}
$$

The slackness condition in (9) means that $A_{t}>0, \mu_{t}=0$ or $A_{t}=0, \mu_{t}>0$. These FOCs, the budget

\footnotetext{
${ }^{4}$ We assume that there is no tax on government bond interest. Indeed, when such a tax exists, the consumer's budget constraint will include the term $r_{t}^{D}\left(1-\tau_{t}^{D}\right) D_{t}$ instead of $r_{t}^{D} D_{t}$. In this case, the non-arbitrage condition between private assets and government bonds is $r_{t}^{A}\left(1-\tau_{t}^{A}\right)=r_{t}^{D}\left(1-\tau_{t}^{D}\right)$, which implies $r_{t}^{A}=r_{t}^{D}$ and $\tau_{t}^{A}=\tau_{t}^{D}$. For simplification purpose, we do not impose any tax on government bonds and consequently the implied non-arbitrage condition (see also below) will become equation (10).
} 
constraint, and the transversality condition $\lim _{t \rightarrow+\infty} \beta^{t} U^{\prime}\left(C_{t}\right) A_{t+1}=0$ will provide a solution of the consumer's optimization program.

Solving for an interior solution $\left(A_{t}>0\right)$, conditions (7)-(9) give:

$$
r_{t}^{D}=r_{t}^{A}\left(1-\tau_{t}\right)
$$

The equality between the interest rate of domestic debt and the net interest rate of private asset given in (10) represents the non-arbitrage condition between holding domestic debt and holding private capital. Furthermore, conditions (6) and (8) give

$$
\frac{U^{\prime}\left(C_{t-1}\right)}{U^{\prime}\left(C_{t}\right)}=\beta\left(1+r_{t}^{D}\right)
$$

which is the usual Keynes-Ramsey rule which states that the marginal utility of past consumption is equal to the discounted marginal utility of current consumption times the interest rate.

By using the expression of the utility function, equation (11) becomes

$$
\frac{C_{t}}{C_{t-1}}=\beta\left(1+r_{t}^{D}\right)
$$

\subsection{Government}

We assume that at each period $t$ the government can collect tax on returns to assets held by private agents. It can also borrow from the domestic and international financial markets, which correspond to two types of public debt, domestic debt $D_{t}$ with interest rate $r_{t}^{D}$ and external debt $B_{t}$ with interest rate $r_{t}^{B}$. As the country has no power on the international financial market, $\left\{r_{t}^{B}\right\}_{t=0}^{\infty}$ is a sequence of exogenous external interest rates. On the spending side, the government can share its resources between public expenditure devoted to production of final goods and reimbursement of interests and capital of domestic and external debts. ${ }^{5}$

\footnotetext{
${ }^{5}$ Recall that we distinguish two types of public debt, domestic debt and external debt, whereas most of existing theoretical studies only considered domestic debt (e.g. Battaglini and Coate 2008, Greiner, 2007, Elmendorf and Mankiw 1999, among others).
} 
The government budget constraint can be expressed as follows: ${ }^{6}$

$$
G_{t}+\left(r_{t}^{B}+1\right) B_{t}+\left(r_{t}^{D}+1\right) D_{t}=\tau_{t} r_{t}^{A} A_{t}+B_{t+1}+D_{t+1}
$$

where $A_{t}$ is the stock of assets held by private agents, $\tau_{t}$ is the tax rate on returns to assets, $r_{t}^{A}$ is the interest rate of asset, and $G_{t}$ is the flow of government expenditure.

Following Greiner (2007), we assume that public debt is not over a certain proportion of total output in order to guarantee sustainability of public debt:

$$
G_{t}+\eta\left(B_{t}+D_{t}\right) \leq \phi Y_{t}+\tau_{t} r_{t}^{A} A_{t}
$$

with $\phi$ and $\eta \in \mathbb{R}$ are constants. Parameter $\phi$ determines whether the level of the primary surplus rises or falls with an increase in gross domestic income. Parameter $\eta$ determines how strong the primary surplus reacts to changes in domestic debt and external debt, $\eta$ may be considered as a feedback parameter of domestic debt and external debt. As in Bohn (1998), Greiner (2007), Greiner et al. (2007), we have $\eta>0$.

Inequality (14) means that total government expenditure and government's borrowing are not exceeded government's revenue which comes from tax collection and a certain proportion of total output. Equation (14) can be also rewritten as

$$
G_{t}-\tau_{t} r_{t}^{A} A_{t}+\eta\left(B_{t}+D_{t}\right) \leq \phi Y_{t}
$$

This condition means that budget deficit $\left(G_{t}-\tau_{t} r_{t}^{A} A_{t}\right)$ can be financed by domestic and external debt, which can be covered by a proportion of production. This condition is motivated by some empirical facts through the Maastricht criteria for the Eurozone countries (public debt lower than $60 \%$ of GDP, budget deficit is lower than $3 \%$ of GDP), thresholds of public debt set in some developing countries, and the discussion about the relation between public debt and growth since the seminal paper of Reinhart and Rogoff (2010). ${ }^{7}$ We also observe that when the equality in

\footnotetext{
${ }^{6}$ All variables are expressed in terms of real values.

${ }^{7}$ Reinhart and Rogoff (2010) and Herndon et al. (2014) showed that public debt has a positive impact on economic growth and there is a higher ratio of public debt to GDP leads to a lower GDP growth rate. For instance, if the ratio of public debt to GDP is lower than 30\%, the average GDP growth rate is about 4.1\%. On the contrary, the growth rate is reduced to $2.2 \%$ if the ratio of public debt to GDP becomes larger than $90 \%$. In a study on the role of government debt on economic growth across twelve Euro-area countries, Checherita and Rother (2010) found that
} 
equation (14) holds, it can be rewritten as

$$
\frac{\tau_{t} r_{t}^{A} A_{t}-G_{t}}{Y_{t}}=-\phi+\eta \frac{B_{t}+D_{t}}{Y_{t}}
$$

This equation corresponds to the positive linear relation between the ratio of primary surplus to GDP and the ratio of debt to GDP found by Bohn (1998) and subsequently confirmed by Greiner et al. (2007).

Let $r_{t-1}^{B D}$ denote the interest rate which satisfies:

$$
B_{t-1} r_{t-1}^{B}+D_{t-1} r_{t-1}^{D}=\left(B_{t-1}+D_{t-1}\right) r_{t-1}^{B D}
$$

or equivalently,

$$
r_{t}^{B D}=\frac{B_{t}}{B_{t}+D_{t}} r_{t}^{B}+\frac{D_{t}}{B_{t}+D_{t}} r_{t}^{D}
$$

Equation (16) indicates that $r_{t-1}^{B D}$ is an average interest rate of $r_{t-1}^{B}$ and $r_{t-1}^{D}$. There always exists an interest rate $r_{t-1}^{B D}$ with given $r_{t-1}^{B}, r_{t-1}^{D}, B_{t-1}$ and $D_{t-1}$. Equation (15) can be rewritten as follows:

$$
B_{t-1}\left(1+r_{t-1}^{B}-\eta\right)+D_{t-1}\left(1+r_{t-1}^{D}-\eta\right)=\left(B_{t-1}+D_{t-1}\right)\left(1+r_{t-1}^{B D}-\eta\right) .
$$

The following lemma shows that at equilibrium (which will be defined below), condition (14) must bind.

Lemma 1 Assume, at equilibrium, for any $t, \eta<r_{t}^{B}$. Then condition (14) must bind.

Proof. Suppose in (14) we have strict inequality:

$$
G_{t}+\eta\left(B_{t}+D_{t}\right)<\phi H K_{t}^{\alpha} G_{t}^{1-\alpha}+\tau_{t} r_{t}^{A} A_{t}
$$

Let $\Delta B_{t}=-\frac{\Delta G_{t}}{1+r_{t}^{B}}$ with $\Delta G_{t}>0$. Equation (13) still holds.

public debt and economic growth have a nonlinear relation and that a higher public debt-to-GDP ratio is on average associated with a lower long-term growth rate when debt is above the range of $90-100 \%$ of GDP. In practice, the ratio of public debt to GDP in each country is different, for example, in European countries where it is regulated at the level of $60 \%$ of GDP following the Maastricht criteria. In the case of developing countries such as Vietnam, the figure is $65 \%$. 
In (14) we have on the LHS, $\Delta G_{t}+\eta \Delta B_{t}=\left(1-\frac{\eta}{1+r_{t}^{B}}\right) \Delta G_{t}>0$. So we can increase $G_{t}$ without violating (14) and increase $Y_{t}$ hence $C_{t}$. This is a contradiction because an increase in consumption will increase the consumer's utility which is already at its highest level at the equilibrium.

Suppose we are at equilibrium. Together (13), (14) and (15) lead to

$$
B_{t}+D_{t}=\left(B_{t-1}+D_{t-1}\right)\left(1+r_{t-1}^{B D}-\eta\right)+\phi Y_{t-1}
$$

We now look at the sustainability of public debt. Following Greiner's (2007) terms, sustainability of public debt states that the current value of public debt must equal the sum of discounted future non-interest surpluses. The sufficient condition for the sustainability of public debt is summarized in the following proposition.

Proposition 1 Define that $\gamma_{t}$ is growth rate of gross domestic income $Y_{t}$, and $r_{t}^{B D}$ is determined by equation (16). The sufficient condition for the sustainability of public debt is $\max \left\{\sup _{t} \gamma_{t}, 0\right\}<$ $\inf _{t} r_{t}^{B D}-\eta$.

Proof. Equation (18) can be expressed as follows (using equation (17)):

$$
B_{t}+D_{t}=\left(B_{0}+D_{0}\right) \prod_{j=1}^{t}\left(1+r_{t-j}^{B D}-\eta\right)+\sum_{s=1}^{t} \phi Y_{t-s} \prod_{j=1}^{s-1}\left(1+r_{t-j}^{B D}-\eta\right)
$$

which is equivalent to

$$
B_{0}+D_{0}=\frac{B_{t}+D_{t}}{\prod_{j=1}^{t}\left(1+r_{t-j}^{B D}-\eta\right)}-\frac{\sum_{s=1}^{t} \phi Y_{t-s} \prod_{j=1}^{s-1}\left(1+r_{t-j}^{B D}-\eta\right)}{\prod_{j=1}^{t}\left(1+r_{t-j}^{B D}-\eta\right)}
$$

Sustainability of public debt is characterized by

$$
B_{0}+D_{0}=\lim _{t \rightarrow \infty}\left(\frac{B_{t}+D_{t}}{\prod_{j=1}^{t}\left(1+r_{t-j}^{B D}-\eta\right)}\right)
$$

Condition (21) is verified if

$$
\lim _{t \rightarrow \infty} \frac{\sum_{s=1}^{t} \phi Y_{t-s} \prod_{j=1}^{s-1}\left(1+r_{t-j}^{B D}-\eta\right)}{\prod_{j=1}^{t}\left(1+r_{t-j}^{B D}-\eta\right)}=0
$$


Denote that $\gamma_{t}$ is the growth rate of total production income $Y_{t}$. Hence, $Y_{t-s}=\prod_{j=0}^{t-s}\left(1+\gamma_{j}\right) Y_{0}$. We then get

$$
\begin{aligned}
\frac{\sum_{s=1}^{t} \phi Y_{t-s} \prod_{j=1}^{s-1}\left(1+r_{t-j}^{B D}-\eta\right)}{\prod_{j=1}^{t}\left(1+r_{t-j}^{B D}-\eta\right)} & =\phi Y_{0} \frac{\sum_{s=1}^{t} \prod_{j=0}^{t-s}\left(1+\gamma_{j}\right) \prod_{j=1}^{s-1}\left(1+r_{t-j}^{B D}-\eta\right)}{\prod_{j=1}^{t}\left(1+r_{t-j}^{B D}-\eta\right)} \\
& =\phi Y_{0} \sum_{j=1}^{t} \prod_{s=j}^{t}\left(\frac{1+\gamma_{t-s}}{1+r_{t-s}^{B D}-\eta}\right)
\end{aligned}
$$

Hence, if $\max \left\{\sup _{t} \gamma_{t}, 0\right\}<\inf _{t} r_{t}^{B D}-\eta$ then condition (21) is verified .

As our model has domestic debt and external debt, sustainability of debt means that in the long run the discounted value of the sum of two debts cannot exceed the initial total debt (or in other words, current value of public debt must equal the sum of discounted future non-interest surpluses) given in equation (21), which holds if equation (22) is satisfied. This corresponds to the No-PonziGame (NPG) condition for our model. For the Ramsey growth model with (only domestic) public debt, the NPG condition can be found in Heijdra and Van Der Ploeg (2002).

For our model, the NPG condition is satisfied if $\max \left\{\sup _{t} \gamma_{t}, 0\right\}<\inf _{t} r_{t}^{B D}-\eta$. In other words, output growth rate $\gamma_{t}$ should be sufficiently lower than the average interest rate $r_{t}^{B D}$. If output growth rate is higher than $r_{t}^{B D}-\eta$, in this case the expression in (22) will tend to infinity and, consequently, the right-hand side term of equation (20) will converge to minus infinity, implying that the initial total debt cannot be covered (i.e. debt is not sustainable).

\section{Solution}

\subsection{Equilibrium}

Equilibrium of model is a solution of the following equations:

Balancedness of consumer budget:

$$
C_{t}+A_{t+1}+D_{t+1}=\left[r_{t}^{A}\left(1-\tau_{t}\right)+1\right] A_{t}+\left(r_{t}^{D}+1\right) D_{t}+\pi_{t} .
$$

Keynes-Ramsey rule:

$$
\frac{U^{\prime}\left(C_{t-1}\right)}{U^{\prime}\left(C_{t}\right)}=\beta\left(1+r_{t}^{D}\right)
$$


Balancedness of the government budget:

$$
G_{t}+r_{t}^{B} B_{t}+r_{t}^{D} D_{t}+B_{t}+D_{t}=r_{t}^{A} \tau_{t} K_{t}+B_{t+1}+D_{t+1}
$$

Sustainability of debt condition:

$$
G_{t}+\eta\left(B_{t}+D_{t}\right)=\phi Y_{t}+\tau_{t} r_{t}^{A} A_{t}
$$

Market clearing for the capital:

$$
K_{t}=A_{t}
$$

Market clearing for the aggregate good:

$$
C_{t}+K_{t+1}=F\left(K_{t}, G_{t}\right)+K_{t}
$$

Market clearing for the domestic debt:

$$
D_{t+1}+\tau_{t} r_{t}^{K} K_{t}=\left(1+r_{t}^{D}\right) D_{t}
$$

And interest rates of capital and domestic debt:

$$
\begin{aligned}
& r_{t}^{K}=F_{K}^{\prime}\left(K_{t}, G_{t}\right), \\
& r_{t}^{D}=r_{t}^{A}\left(1-\tau_{t}\right) .
\end{aligned}
$$

The equilibrium must also satisfy the NPG condition (for the sustainability of public debt) in Proposition 1 (i.e. $\max \left\{\sup _{t} \gamma_{t}, 0\right\}<\inf _{t} r_{t}^{B D}-\eta$ ) and the transversality condition $\lim _{t \rightarrow+\infty} \beta^{t} U^{\prime}\left(C_{t}\right) K_{t+1}=$ 0.8

\subsection{Steady state}

Let us define $g_{t} \equiv \frac{G_{t}}{K_{t}}, b_{t} \equiv \frac{B_{t}}{K_{t}}, d_{t} \equiv \frac{D_{t}}{K_{t}}, c_{t} \equiv \frac{C_{t}}{K_{t}}$, and $\xi_{k} \equiv \frac{K_{t+1}}{K_{t}}$. The solution for the model with the variables $G_{t}, C_{t}, B_{t}, D_{t}$, and $K_{t}$ is equivalent to the solution with new variables $g_{t}, c_{t}, b_{t}$, and

\footnotetext{
${ }^{8}$ The aggregation of market clearing conditions for the final good and the domestic debt gives the consumer's budget constraint.
} 
$d_{t}$. Equations (13), (14), (5), (12), and the good market clearing condition become

$$
\begin{aligned}
g_{t}+\left(1+r_{t}^{B}\right) b_{t}+\left(1+r_{t}^{D}\right) d_{t} & =r_{t}^{K} \tau_{t}+\left(b_{t+1}+d_{t+1}\right) \xi_{k}, \\
\tau_{t} r_{t}^{K}-g_{t} & =\eta\left(b_{t}+d_{t}\right)-\phi H g_{t}^{1-\alpha}, \\
\frac{c_{t+1}}{c_{t}} \xi_{k} & =\beta\left(1+r_{t}^{D}\right), \\
c_{t}+\xi_{k}+d_{t+1} \xi_{k} & =1+\left(1-\tau_{t}\right) r_{t}^{K}+\left(1+r_{t}^{D}\right) d_{t}+H g_{t}^{1-\alpha}-r_{t}^{K},
\end{aligned}
$$

where (from the good market clearing condition)

$$
\xi_{k}=H g_{t}^{1-\alpha}+1-c_{t}
$$

By substituting equation (4) into equations (23)-(26) and by using the non arbitrage condition (10), we get the following system

$$
\begin{aligned}
& g_{t}+\left(1+r_{t}^{B}\right) b_{t}+\left[1+\left(1-\tau_{t}\right) \alpha H g_{t}^{1-\alpha}\right] d_{t}=\alpha H g_{t}^{1-\alpha} \tau_{t}+\left(b_{t+1}+d_{t+1}\right)\left(H g_{t}^{1-\alpha}+1-c_{t}\right), \\
& \tau_{t} \alpha H g_{t}^{1-\alpha}-g_{t}=\eta\left(b_{t}+d_{t}\right)-\phi H g_{t}^{1-\alpha} \\
& \frac{c_{t+1}}{c_{t}}\left(H g_{t}^{1-\alpha}+1-c_{t}\right)=\beta\left[1+\left(1-\tau_{t}\right) \alpha H g_{t}^{1-\alpha}\right] \\
& c_{t}+\left(1+d_{t+1}\right)\left(H g_{t}^{1-\alpha}+1-c_{t}\right)=\left[1+\left(1-\tau_{t}\right) \alpha H g_{t}^{1-\alpha}\right]\left(1+d_{t}\right)+(1-\alpha) H g_{t}^{1-\alpha} .
\end{aligned}
$$

A balanced growth path equilibrium is defined by $x_{t+1}=x_{t}=x^{*}, x=c, b, d, g$. The system above becomes

$$
\begin{aligned}
& g^{*}+\left(1+r^{B}\right) b^{*}+\left[1+(1-\tau) \alpha H g^{*(1-\alpha)}\right] d^{*}=\alpha H g^{*(1-\alpha)} \tau+\left(b^{*}+d^{*}\right)\left(H g^{*(1-\alpha)}+1-c^{*}(32)\right. \\
& \tau \alpha H g^{*(1-\alpha)}-g^{*}=\eta\left(b^{*}+d^{*}\right)-\phi H g^{*(1-\alpha)}, \\
& H g^{*(1-\alpha)}+1-c^{*}=\beta\left[1+(1-\tau) \alpha H g^{*(1-\alpha)}\right], \\
& c^{*}+\left(1+d^{*}\right)\left(H g^{*(1-\alpha)}+1-c^{*}\right)=\left[1+(1-\tau) \alpha H g^{*(1-\alpha)}\right]\left(1+d^{*}\right)+(1-\alpha) H g^{*(1-\alpha)}
\end{aligned}
$$

We observe that the market clearing condition for domestic debt is rewritten as follows:

$$
d_{t+1} \xi_{k}+\tau r^{K}=\left(1+r^{D}\right) d_{t}
$$


As the interest rates at the BGP are given by $r^{K}=\alpha H g^{*(1-\alpha)}$ and $r^{D}=(1-\tau) r^{K}$, equation (36) gives the expression for domestic debt at the BGP:

$$
d^{*}=\frac{\tau r^{K}}{(1-\beta)\left[1+(1-\tau) r^{K}\right]}=\theta g^{*(1-\alpha)}
$$

with

$$
\theta=\frac{\tau H \alpha}{(1-\beta)\left(1+(1-\tau) H \alpha g^{*(1-\alpha)}\right)}
$$

Moreover, by plugging equation (36) (expressed at the steady state) into (32), we obtain the steadystate value for the external debt:

$$
b^{*}=\frac{g^{*}}{\xi_{k}-\left(1+r^{B}\right)},
$$

where, using equation (25) at the BGP and the expressions of interest rates, $\xi_{k}$ is given by

$$
\xi_{k}=\beta\left(1+r^{D}\right)=\beta\left[1+(1-\tau) r^{K}\right]=\beta\left[1+(1-\tau) \alpha H g^{*(1-\alpha)}\right]
$$

Equation (33) is rewritten as

$$
g^{*}+\eta\left(b^{*}+d^{*}\right)=\phi H g^{*(1-\alpha)}+\tau \alpha H g^{*(1-\alpha)} .
$$

By dividing both sides of this equation by $g^{*}$ (excluding the solution $g^{*}=0$ ) and plugging the expressions of steady values $b^{*}$ and $d^{*}$, we obtain

$$
1+\frac{\eta}{\xi_{k}-\left(1+r^{B}\right)}+\frac{\eta \beta \tau \alpha H}{(1-\beta) \xi_{k} g^{* \alpha}}=\frac{\phi H+\tau \alpha H}{g^{* \alpha}}
$$

This equation gives the solution on the (positive) steady-state value for public expenditure $g^{*}$ in terms of the model's parameters.

\section{Existence, uniqueness, and multiplicity}

Recall that the BGP of the model is entirely characterized by equation (41) which determines $g^{*}$. If this solution exists, then the values for domestic debt $d^{*}$ and external debt $b^{*}$ are given by (37) and (38), respectively. Moreover, equations (27) and (39) give the steady-state value for 
consumption-capital ratio $c^{*}$ :

$$
c^{*}=1-\beta+[1-\beta(1-\tau) \alpha] H g^{*(1-\alpha)} .
$$

The value of the steady-state production is $y^{*}=H g^{*(1-\alpha)}$. Given the properties of $g^{*}$, we can recover those of $b^{*}, d^{*}, c^{*}$ and $y^{*}$. In the following, we discuss the conditions for existence, uniqueness, multiplicity, and non existence of $g^{*}$.

\subsection{Existence and uniqueness of the steady state}

Assume

$$
(1-\tau) H>\frac{1+r^{B}}{\beta}-1
$$

and

$$
\phi+\tau>\frac{\eta \tau}{(1-\beta)(1+(1-\tau) H)}
$$

Lemma 2 Assume (43) and (44). Then when $\alpha$ is close to 1 there exists a unique steady state.

Proof. When $\alpha=1$, equation (41) becomes:

$$
1+\frac{\eta}{\beta[1+(1-\tau) H]-\left(1+r^{B}\right)}+\frac{\eta \tau H}{(1-\beta)[1+(1-\tau) H] g}=\frac{(\phi+\tau) H}{g^{*}}
$$

Or equivalently

$$
1+\frac{\eta}{\beta[1+(1-\tau) H]-\left(1+r^{B}\right)}=\left(\phi+\tau-\frac{\eta \tau}{(1-\beta)[1+(1-\tau) H]}\right) \frac{H}{g^{*}}
$$

Condition (43) ensures $\beta[1+(1-\tau) H]-\left(1+r^{B}\right)>0$ while condition (44) ensures the RHS $>0$.

The solution is

$$
g^{*}=\Theta / \Psi
$$

with

$$
\Theta=\left(\phi+\tau-\frac{\eta \tau}{(1-\beta)[1+(1-\tau) H]}\right) H
$$


and

$$
\Psi=1+\frac{\eta}{\beta[1+(1-\tau) H]-\left(1+r^{B}\right)}
$$

We can conclude that under the assumptions (43) and (44), when $\alpha$ is close to 1 , there exists a unique steady state.

Proposition 2 Let $H$ satisfy $\left(\frac{1+r^{B}}{\beta}-1\right) \frac{1}{H}<1$ or equivalently $\left.H>\bar{H}=\left(\frac{1+r^{B}}{\beta}-1\right)\right)$. Then there exist $\hat{\tau}(H) \in(0,1), \hat{\alpha}<1$ such that if $\tau<\hat{\tau}(H)$ and $\alpha>\hat{\alpha}$, there exists a unique steady state.

Proof. Assume $H$ satisfy $\left(\frac{1+r^{B}}{\beta}-1\right) \frac{1}{H}<1$ (i.e. $H>\bar{H}=\left(\frac{1+r^{B}}{\beta}-1\right)$ ). Then (43) holds if $\tau<\tau_{a}=1-\left(\frac{1+r^{B}}{\beta}-1\right) \frac{1}{H}$. Obviously, given $H$ satisfying $H>\bar{H},(44)$ is satisfied if $\tau$ is very small. That means there exists $\tau_{b}<1$ such that if $\tau<\tau_{b}$ then (44) is satisfied (in other words, $\tau_{b}$ is given by condition (44)). Hence, we take $\hat{\tau}=\min \left\{\tau_{a}, \tau_{b}\right\}$ to end the proof.

This proposition consists of finding $\hat{\tau}$ (which depends on $H>\bar{H}$ ) and $\hat{\alpha}$, to ensure the uniqueness of the steady state.

For the effect of the tax rate on the economy, consider first the case $\alpha=1$. In this situation, equation (46) gives the analytical expression for $g^{*}$ :

$$
g^{*}=\frac{\left(\phi+\tau-\frac{\eta \tau}{(1-\beta)[1+(1-\tau) H]}\right) H}{1+\frac{\eta}{\beta[1+(1-\tau) H]-\left(1+r^{B}\right)}}
$$

We can observe from this expression that the effect of $\tau$ on $g^{*}$ can be of either sign, depending on the parameters $\phi, \eta, \beta, r^{B}$, and $H$. The case $\alpha=1$ corresponds to the $A K$-type production function which is independent of public spending. Figure 1 illustrates the effects of taxation on the model's steady state when $\alpha=1$ and the parameters are fixed at some reasonable values, i.e. $\phi=0.65$, $\eta=0.2, \beta=0.95, r^{B}=0.03, H=10 .^{9}$

In the case $\alpha<1$, we cannot calculate the analytical solution of the model, neither the derivatives of macroeconomic variables w.r.t. $\tau$. The impact of taxation on the BGP can be investigated by simulation. Figure 2 displays the solution when $\alpha=0.6$ while other parameters are fixed at the same values as before. Remark that in this case, we obtain $\bar{H}=0.0842, \tau_{a}=0.9916$, and $\tau_{b}=0.8709$ which, following Proposition 2, ensure the uniqueness of the solution because both conditions on

\footnotetext{
${ }^{9}$ Simulations are run with Matlab. Qualitative results remain very similar with other values for the model's parameters.
} 


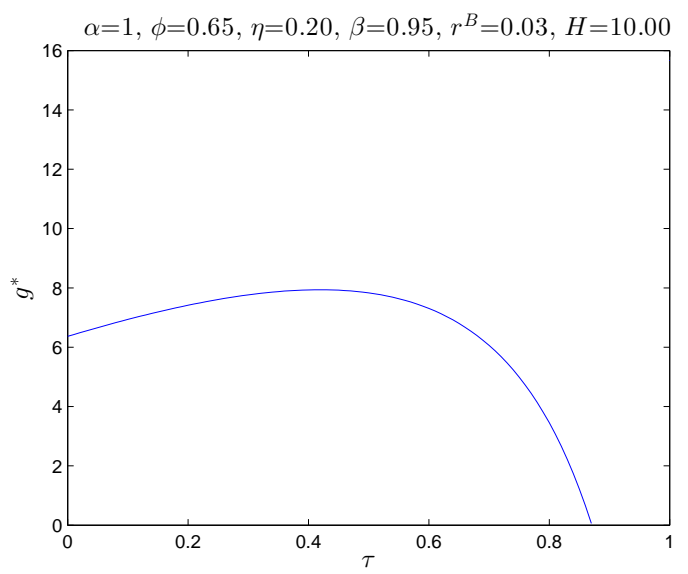

(a) Public spending

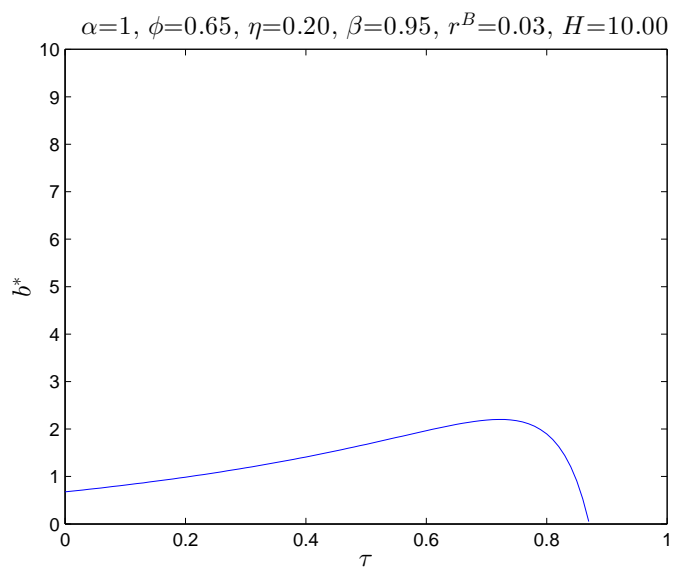

(c) External debt

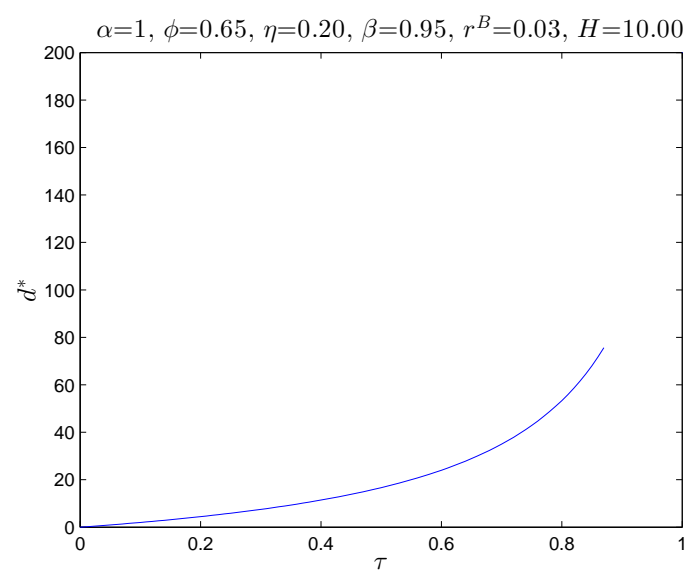

(b) Domestic debt

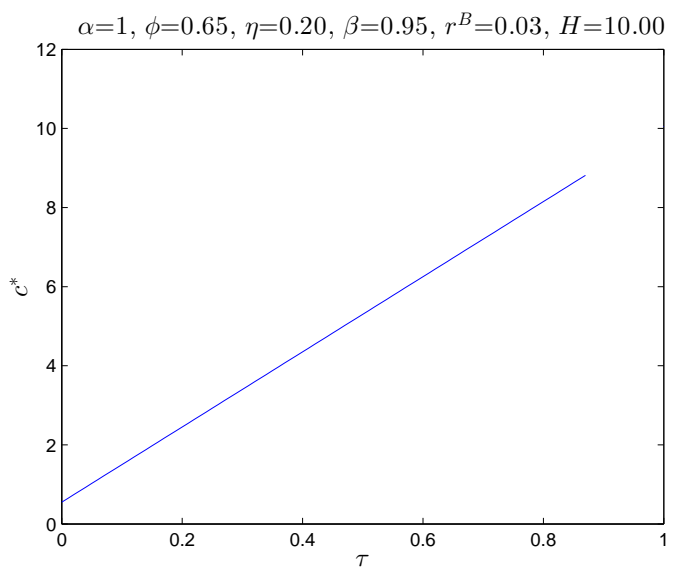

(d) Consumption

Figure 1: Effects of taxation on the steady state, $\alpha=1$.

$H$ and $\tau$ are satisfied (i.e. $H=10>\bar{H}=0.0842$ and $\tau<\hat{\tau}=0.8709$ ). Figures 1 and 2 report similar results about public spending, domestic debt, and external debt. The only difference resides in the relation between $\tau$ and the consumption-capital ratio. In the case $\alpha=1$ this relation is monotonously increasing whereas in the case $\alpha<1$ it corresponds to a bell-shaped relation.

\subsection{Multiplicity of steady states}

We rewrite equation (41) as follows:

$$
1+\frac{\eta}{\xi_{k}-\left(1+r^{B}\right)}=\left[\phi+\tau \alpha-\frac{\eta \beta \tau \alpha}{(1-\beta) \xi_{k}}\right] \frac{H}{g^{* \alpha}}
$$




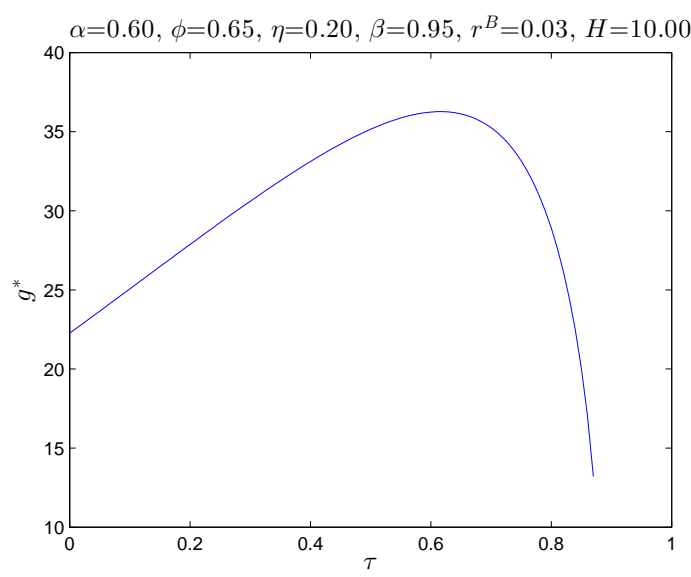

(a) Public spending

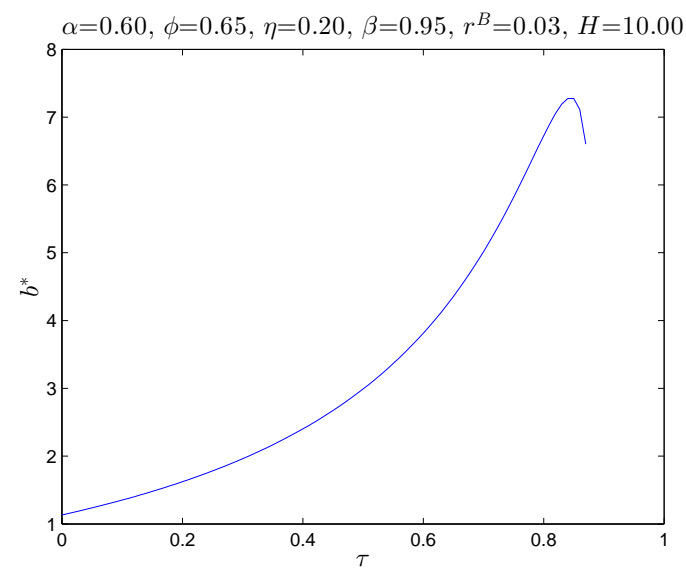

(c) External debt

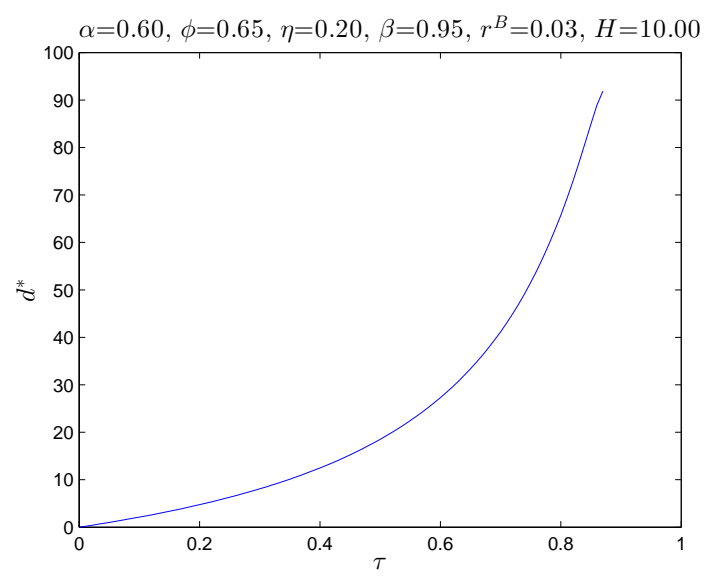

(b) Domestic debt

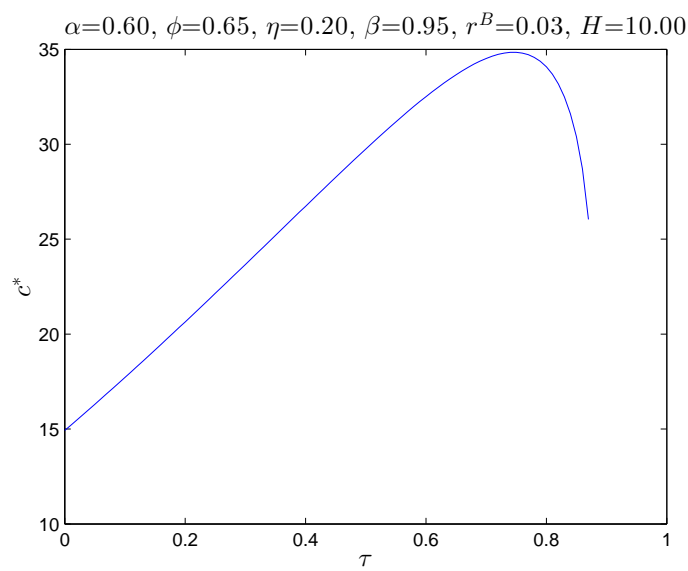

(d) Consumption

Figure 2: Effects of taxation on the steady state, $\alpha=0.6$.

We denote $\operatorname{LHS}\left(g^{*}\right)=1+\frac{\eta}{\xi_{k}-\left(1+r^{B}\right)}$ and $\operatorname{RHS}\left(g^{*}\right)=\left[\phi+\tau \alpha-\frac{\eta \beta \tau \alpha}{(1-\beta) \xi_{k}}\right] \frac{H}{g^{* \alpha}}$. We must impose that $g^{*}$ satisfies

$$
\xi_{k}-\left(1+r^{B}\right)=\beta\left(1+(1-\tau) H \alpha g^{*(1-\alpha)}\right)-\left(1+r^{B}\right)>0
$$

to ensure $b^{*}>0$. Let $\tilde{g}=\left[\frac{1+r^{B}-\beta}{\beta(1-\tau) H \alpha}\right]^{\frac{1}{1-\alpha}}$ for which $\xi_{k}-\left(1+r^{B}\right)=0$.

Lemma 3 If $\tau \alpha\left(\frac{\eta}{1-\beta}-1\right)<\phi$ then $R H S\left(g^{*}\right)>0$ for any $g^{*}>0$, for any $H>0$.

Proof. We have, since $\xi_{k}=\beta\left(1+r^{D}\right)$ (equation (25) at the BGP) and $r^{D} \geq 0$,

$$
\phi+\tau \alpha>\frac{\eta \tau \alpha}{1-\beta} \Rightarrow \phi+\tau \alpha>\frac{\eta \tau \alpha \beta}{(1-\beta) \xi_{k}}
$$

and

$$
\left.\phi+\tau \alpha>\frac{\eta \tau \alpha}{1-\beta} \Leftrightarrow \tau \alpha\left(\frac{\eta}{1-\beta}-1\right)\right)<\phi
$$


We first choose $\tau_{1}$ as follows.

- If $\frac{\eta}{1-\beta}-1 \leq 0$, choose $\tau_{1}<1$.

- If $\frac{\eta}{1-\beta}-1>0$ then choose $\tau_{1}<\min \left\{1, \frac{\phi}{\alpha\left(\frac{\eta}{1-\beta}-1\right)}\right\}$.

We have obviously

$$
Z=\inf _{0 \leq \tau \leq \tau_{1}}\left[\phi+\tau \alpha-\frac{\eta \beta \tau \alpha}{(1-\beta) \xi_{k}(1)}\right]>0
$$

where $\xi_{k}(1)$ is the value of $\xi_{k}$ at $g^{*}=1$. Note that we always have $H \times Z \leq \operatorname{RHS}(1)$.

Lemma 4 Let $H_{1}\left(\tau_{1}\right)>\frac{1+r^{B}-\beta}{\beta\left(1-\tau_{1}\right) \alpha}$. For any $H \geq H_{1}\left(\tau_{1}\right)$, any $\tau \leq \tau_{1}$, we have $\beta(1-\tau) H \alpha-(1+$ $\left.r^{B}-\beta\right)>0$.

Proof. We have

$$
\beta(1-\tau) H \alpha-\left(1+r^{B}-\beta\right) \geq \beta\left(1-\tau_{1}\right) H_{1} \alpha-\left(1+r^{B}-\beta\right)>0
$$

Proposition 3 There exist $\tau_{1}$ and $\hat{H}\left(\tau_{1}\right)$ such that if $\tau \leq \tau_{1}$ and $H \geq \hat{H}\left(\tau_{1}\right)$, we have a steady state $g_{1}^{*}>1$ and another steady state $g_{2}^{*} \in(\tilde{g}, 1)$.

\section{Proof.}

- We first prove there exists a steady state $g_{1}^{*}>1$.

- When $g^{*} \rightarrow+\infty$, we have $\operatorname{LHS}\left(g^{*}\right)>\operatorname{RHS}\left(g^{*}\right)$.

- We will show $\operatorname{LHS}(1)<\operatorname{RHS}(1)$. We have, for any $H \geq H_{1}\left(\tau_{1}\right)$, any $\tau \leq \tau_{1}$ :

$$
\operatorname{LHS}(1)=1+\frac{\eta}{\beta(1-\tau) H \alpha-\left(1+r^{B}-\beta\right)} \leq W=1+\frac{\eta}{\beta\left(1-\tau_{1}\right) H_{1} \alpha-\left(1+r^{B}-\beta\right)}
$$

Let

$$
H_{2}\left(\tau_{1}\right)=\frac{W}{Z}
$$


For any $H>H_{2}\left(\tau_{1}\right)$ we have

$$
\operatorname{LHS}(1) \leq W=Z H_{2}\left(\tau_{1}\right)<Z H \leq \operatorname{RHS}(1)
$$

Choose $\hat{H}\left(\tau_{1}\right)=\max \left\{H_{1}\left(\tau_{1}\right), H_{2}\left(\tau_{1}\right)\right\}$. If $\tau \leq \tau_{1}$ and $H \geq \hat{H}\left(\tau_{1}\right)$ then $\operatorname{LHS}(1)<\operatorname{RHS}(1)$.

- We conclude there exists a steady state $g_{1}^{*}>1$.

- We now prove there exists another steady state $g_{2}^{*} \in(\tilde{g}, 1)$ where $\tilde{g}=\left[\frac{1+r^{B}-\beta}{\beta(1-\tau) H \alpha}\right]^{\frac{1}{1-\alpha}}$.

From Lemma 4, $\tilde{g}<1$. When $g^{*} \downarrow \tilde{g}, \operatorname{LHS}\left(g^{*}\right) \rightarrow+\infty$ while $\operatorname{RHS}\left(g^{*}\right)$ converges to a finite value. Hence $\operatorname{LHS}\left(g^{*}\right)>\operatorname{RHS}\left(g^{*}\right)$ when $g^{*}$ is close to $\tilde{g}$. We have already proved that $\operatorname{LHS}(1)<$ RHS(1). The conclusion follows.

For our numerical example, we can set $\tau_{1}<\frac{\phi}{\alpha *\left(\frac{\eta}{1-\text { beta }}-1\right)}=0.3611, H_{1}>\frac{1+r^{B}-\beta}{\beta\left(1-\tau_{1}\right) \alpha}=0.2197$. For example, if we choose $\tau_{1}=0.3511$ and $H_{1}=1.2163$, then $H_{2}=2.3704$. As a result, Proposition 3 shows that there is multiple steady states if $\tau<0.3511$ and $H \geq \hat{H}=\max \left\{H_{1}, H_{2}\right\}=2.3704$.

\subsection{Non existence of steady states}

Proposition 4 There exists $\tilde{H}$ such that if $H<\tilde{H}$ then there exists no steady states.

Proof. We rewrite equation (47) as follows

$$
1+\frac{\eta}{\xi_{k}-\left(1+r^{B}\right)}-\left[\phi+\tau \alpha-\frac{\eta \beta \tau \alpha}{(1-\beta) \xi_{k}}\right] \frac{H}{g^{* \alpha}}=0
$$

Or equivalently

$$
1-(\phi+\tau \alpha) \frac{H}{g^{* \alpha}}+\frac{\eta}{\xi_{k}-\left(1+r^{B}\right)}+\frac{\eta \beta \tau \alpha}{(1-\beta) \xi_{k}} g^{* \alpha}=0
$$

Consider the expression $1-(\phi+\tau \alpha) \frac{H}{g^{* \alpha}}$ or $\left(g^{* \alpha}-(\phi+\tau \alpha) H\right)$ for $g^{*}>\tilde{g}$ where $\tilde{g}=\left[\frac{1+r^{B}-\beta}{\beta(1-\tau) H \alpha}\right]^{\frac{1}{1-\alpha}}$. We have $g^{* \alpha}-(\phi+\tau \alpha) H>\tilde{g}^{\alpha}-(\phi+\tau \alpha) H$ and

$$
\tilde{g}^{\alpha}-(\phi+\tau \alpha) H=\frac{\left[1+r^{B}-\beta\right]^{\frac{\alpha}{1-\alpha}}-(\phi+\tau \alpha)[\beta(1-\tau) \alpha]^{\frac{\alpha}{1-\alpha}} H^{\frac{1}{1-\alpha}}}{[\beta(1-\tau) \alpha H]^{\frac{\alpha}{1-\alpha}}} .
$$


Let $M(\alpha, \beta, \phi)=\max _{0 \leq \tau \leq 1}\left\{(\phi+\tau \alpha)[\beta(1-\tau) \alpha]^{\frac{\alpha}{1-\alpha}}\right\} \geq \phi(\beta \alpha)^{\frac{\alpha}{1-\alpha}}>0$.

Let $\tilde{H}=\frac{\left(1+r^{B}-\beta\right)^{\alpha}}{M(\alpha, \beta, \phi)^{1-\alpha}}$. Then if $H<\tilde{H}$ we have $\tilde{g}^{\alpha}-(\phi+\tau \alpha) H>0$. Hence, for any $g^{*}>\tilde{g}$, $g^{* \alpha}-(\phi+\tau \alpha) H>0$. This implies

$$
1-(\phi+\tau \alpha) \frac{H}{g^{* \alpha}}+\frac{\eta}{\xi_{k}-\left(1+r^{B}\right)}+\frac{\eta \beta \tau \alpha}{(1-\beta) \xi_{k}} g^{* \alpha}>0
$$

for any $g^{*}>\tilde{g}$.

There exists no positive steady state.

For our numerical example (i.e. $\alpha=0.6, \phi=0.65, \eta=0.2, \beta=0.95, r^{B}=0.03, H=10$ ), function $M(\alpha, \beta, \phi)$ is maximized at $\tau=0$ (its maximum value is $M=0.2797$ ), which gives $\tilde{H}=0.7855$. Hence, there is no positive BGP if the productivity $H$ is lower than this value. Our numerical example with $H=10$ clearly excludes this case.

\section{Discussion}

Proposition 2 imposes conditions on the tax rate $\tau$ and the productivity $H$ in order to have the existence and the uniqueness of the steady state. Proposition 3 discusses conditions on $\tau$ and $H$ which give rise to at least two steady states. Following these propositions, the existence of a nontrivial (positive) steady state requires a sufficiently large productivity $H$ and a sufficiently low tax on returns to assets. Otherwise, if the productivity $H$ is small as indicated in Proposition 4, we have no positive steady state.

Figures 1 and 2 also provide the effects of an increase in the tax rate on returns to assets on the steady state. In particular, the relation between public spending and the tax rate has a bell shape. Domestic debt unambiguously increases with tax rate whereas external debt displays an inverted U shape. Consequently, a high tax rate leads to a reallocation of public debt in favor of domestic debt (to the detriment of external debt) because public spending decreases and domestic debt is more attractive than holding physical assets. The effect of taxation on consumption (and production) also displays a nonlinear pattern when the output elasticity of capital is lower than unity (i.e. in the case of Cobb-Douglas production function) whereas the effect is monotonously increasing in the case of unit elasticity (i.e. $A K$ production function). 
These findings can be explained as follows. An increase of tax on returns to assets $(\tau)$ will lead to a decrease of net revenue relative to physical assets hold by the consumer. Thus, the consumer will decrease their investment in physical capital and devote her income to buy government bond (i.e. domestic debt increases) and consumption good until the non arbitrage condition holds $\left(r^{D}=(1-\tau) r^{K}\right)$ and her budget constraint is binding. Tax increase will rise tax revenue which allows for an increase in public spending. However, as the latter is not entirely financed by domestic debt and tax revenue, the government has recourse to a higher external debt. When the tax rate is too high, tax revenue will decrease and the government must cut down his spending. A high tax rate also implies that external debt becomes relatively more expensive than domestic debt from the government's point of view (which must comply with the sustainability condition of public debt) as $r^{D}$ is relatively lower than $r^{B}$ (which is exogenously fixed by the international financial market), leading to a decrease of external debt. This finding is supported by the observation that several developing and emerging countries have recently adopted aggressive policies aimed at substituting external debt with domestic debt (Panizza 2008, Presbitero 2012).

In the case $\alpha=1$, output always increases with tax on returns to assets as the variation in public spending has no effect on production. When $\alpha<1$, as public spending becomes a production input, production of consumption good varies in accordance with the dynamics of public spending which corresponds to a bell-shaped relation of the tax rate. In particular, when tax is sufficiently high, output and then consumption will fall as public spending diminishes.

In the case of multiplicity, the result shows that under some circumstances and despite of a relatively high productivity $(H<\hat{H})$, there can exists at least two steady states: one corresponds to a low public spending, another to a high public spending. From equation (37) it is easy to find that

$$
\frac{\partial d^{*}}{\partial g^{*}}=\frac{\tau \frac{\partial r^{K}}{\partial g^{*}}}{\left[(1-\beta)\left(1+(1-\tau) r^{K}\right)\right]^{2}} \geq 0
$$

This implies that a low (high) steady-state value of public spending corresponds to a low (high) value of domestic debt. Furthermore, from equation (38), the sign of $\partial b^{*} / \partial g^{*}$ can be negative or positive. However, we can observe from (38) that $\lim _{g^{*} \rightarrow \tilde{g}} b^{*}>0$ and $\lim _{g^{*} \rightarrow+\infty} b^{*}=\frac{g^{* \alpha}}{\beta(1-\tau) \alpha(1-\alpha) H} \rightarrow+\infty$ (using the l'Hôpital's rule). Consequently, there is a steady state with low public spending, low production, low consumption, low domestic debt, and a non ignorable external debt (as $\lim _{g^{*} \rightarrow \tilde{g}} b^{*}>$ 
0). The other steady state corresponds to high public spending, high production, high consumption, high domestic debt, and high external debt.

Our results also show that if productivity is too low, i.e. lower than $\tilde{H}$, a non trivial BGP cannot exist (the only one is zero). It implies that an economy must have a sufficient productivity to expect the existence of a positive growth path and possibly to escape the poverty trap (or zero equilibrium).

Consider the growth rate of the economy (i.e. $Y_{t+1} / Y_{t}$ ) at the BGP. It is given by (using equation $(39))$

$$
\xi_{y}=\xi_{k}=\beta\left[1+(1-\tau) \alpha H g^{*(1-\alpha)}\right] .
$$

At the BGP, public spending always has a positive effect on the growth rate when $\alpha<0$, contradicting the finding of Greiner (2007) about the negative effect of public investment. If $\alpha=1$ there is naturally no effect of public spending on the steady-state growth rate.

Regarding the impact of taxation on the steady-state growth rate, if $\alpha=1$ the effect of $\tau$ on the $\xi_{y}$ is always negative, meaning that an increase in tax on returns to assets is detrimental to public spending (by the reasoning above) and therefore harmful to growth. In the general case with $\alpha<1$, the effect of tax on the steady-state growth rate is

$$
\frac{\partial \xi_{y}}{\partial \tau}=\alpha \beta H g^{*(-\alpha)}\left[(1-\tau)(1-\alpha) \frac{\partial g^{*}}{\partial \tau}-g^{*}\right]
$$

We observe that if $\frac{\partial g^{*}}{\partial \tau}<0$, i.e. we are on the downward sloping part of the relation between $g^{*}$ and $\tau$ (see Figure 2a), then $\frac{\partial \xi_{y}}{\partial \tau}<0$ : an increase in tax rate reduces the balanced growth rate. If we are on the upward sloping part of the relation between $g^{*}$ and $\tau$ (i.e. $\frac{\partial g^{*}}{\partial \tau} \geq 0$ ), we have

$$
\frac{\partial \xi_{y}}{\partial \tau} \geq 0 \quad \text { if } \quad \frac{\partial g^{*}}{\partial \tau} \geq \frac{g^{*}}{(1-\tau)(1-\alpha)}>0
$$

This result indicates that the effect of tax on the balanced growth rate can be positive, negative, or nonlinear (first positive and then negative). Tax on returns to assets can foster growth at the steady state if the following conditions are met: (i) public spending rises and (ii) the steady-state public spending is sufficiently low and/or output elasticity of public spending is sufficiently large. This finding interestingly differs from the existing literature and appears very insightful. Indeed, 
this general theoretical result can be employed to explain the existing conflicting results, e.g. the positive impact of capital income and corporate income taxes and the negative impact of labor income tax on economic growth (Angelopoulos et al., 2007), the negative impact of tax rate on economic growth (Cebula 1995, Lee et al. 1997, Kneller et al. 1999, and Lee and Gordon 2005), and the inverted $U$ relationship between the balanced growth rate and the income tax rate (Futagami et al., 1993). Following certain conditions, we can recover these results. For example, using the same parameters values as in the previous numerical exercise, we obtain a monotonous decreasing relationship between the tax rate and the balanced growth rate. If we choose a higher value for $1-\alpha$ (for example $1-\alpha=0.7$, i.e. $\alpha=0.3$ ) while keeping the same values for other parameters, an inverted U relation emerges.

\section{Conclusion}

In this paper, we investigate the relationship between government expenditure, tax on asset returns, economic growth, and public debt in an endogenous growth framework à la Barro. We consider two types of public debt: domestic debt and external debt. The main results of the paper can be summarized as follows.

1. For the existence of a positive BGP, the economy should have a sufficiently large productivity and a sufficiently low tax on returns to assets. If productivity is too low, the nontrivial steady state cannot exist.

2. The analysis supports the nonlinear (or bell shaped) effect of taxation on public spending, output and consumption (particularly in the case of output elasticity of public spending lower than unity). This result is similar to the Laffer curve.

3. A high tax rate reallocates the composition of public debt in favor of domestic debt (to the detriment of external debt). More precisely, an increase in tax rate can boost external debt as long as tax rate does not exceed a certain threshold, otherwise, the relation is decreasing. This result is supported by the policy recently implemented in several countries where external public debt is substituted by its domestic counterpart.

4. Public spending always has a positive effect on the balanced growth rate. 
5. The analysis shows that the effect of tax on the balanced growth rate depends on several conditions. It can be positive, negative, or follow an inverted U relation. An increase in the tax rate is harmful to growth if it reduces public spending (i.e. when $\tau$ is sufficiently high).

Tax can enhance growth if it rises public spending when the latter is low enough and/or the output elasticity of public spending is sufficiently large.

In a further study, we will develop a dynamic analysis and the welfare aspect of this model. It would also be worth addressing the question of optimal growth and investigating how the tax rate can be set in order to maximize welfare. It is also interesting to include other kinds of tax in the theoretical model and to empirically reassess the impact of taxation on economic growth by focusing on the types of public spending (productive versus unproductive public spending). Such a study would help to provide some guidelines regarding fiscal policy that a country can implement to sustain economic growth. 


\section{References}

Angelopoulos, K., Economides, G., and Kammas, P. (2007). Tax-spending policies and economic growth: theoretical predictions and evidence from the OECD. European Journal of Political Economy, 23(4):885-902.

Aschauer, D. A. et al. (1989). Public investment and productivity growth in the group of seven. Economic Perspectives, 13(5):17-25.

Barro, R. J. (1990). Government spending in a simple model of endogenous growth. Journal of Political Economy, 98:S103-S125.

Battaglini, M. and Coate, S. (2008). A dynamic theory of public spending, taxation, and debt. American Economic Review, 98(1):201-236.

Bohn, H. (1998). The behaviour of U.S. public debt and deficits. Quarterly Journal of Economics, 113(3):949-963.

Bom, P. and Ligthart, J. (2014). Public infrastructure investment, output dynamics, and balanced budget fiscal rules. Journal of Economic Dynamics and Control, 40:334-354.

Calvo, G. (1997). Capital flows: Emerging issues. Policy Notes, Columbia University, http://www.columbia.edu/gc2286/documents/ciecpp1.pdf.

Calvo, G. and Reinhart, C. M. (2002). Fear of floating. Quarterly Journal of Economics, 117(2):379408.

Checherita, C. and Rother, P. (2010). The impact of high and growing government debt on economic growth: An empirical investigation for the euro area. European Central Bank Working Paper Series n. 1237.

Clements, B. J., Bhattacharya, R., and Nguyen, T. Q. (2003). External debt, public investment, and growth in low-income countries. IMF Working Paper 2003-2249, International Monetary Fund.

Dell'Erba, S., Hausmann, R., and Panizza, U. (2013). Debt levels, debt composition, and sovereign spreads in emerging and advanced economies. Oxford Review of Economics Policy, 29(3):518-547.

Devarajan, S., Swaroop, V., and Zou, H.-f. (1996). The composition of public expenditure and economic growth. Journal of Monetary Economics, 37(2):313-344.

Drazen, A. (2000). Political Economy in Macroeconomics. Princeton University Press, New Jersey.

Ejigayehu, D. A. (2003). The effect of external debt on economic growth - panel data analysis on the relationship between external debt and economic growth. Department of Economics, Södertörn University.

Elmendorf, D. W. and Mankiw, N. G. (1999). Government debt. In Taylor, J. B. and Woodfort, M., editors, Handbook of Macroeconomics, volume 1C, chapter 25, pages 1615-1669. Elsevier.

Felice, G. (2016). Size and composition of public investment, sectoral composition and growth. European Journal of Political Economy, 44(C):136-158.

Ferreira de Mendonça, H. and Rangel Machado, M. (2014). Public debt management and credibility: Evidence from an emerging economy. Economic Modelling, 30:10-21.

Futagami, K., Iwaisako, T., and Ohdoi, R. (2008). Debt policy rule, productive government spending and multiplie growth paths. Macroeconomic Dynamics, 12(4):445-462. 
Futagami, K., Morita, Y., and Shibata, A. (1993). Dynamic analysis of an endogenous growth model with public capital. Scandinavian Journal of Economics, 95:607-625.

Glomm, G. and Ravikumar, B. (1997). Productive government expenditures and long-run growth. Journal of Economic Dynamics and Control, 21(1):183-204.

Greiner, A. (2007). An endogenous growth model with public capital and sustainable government debt. Japanese Economic Review, 58(3):345-361.

Greiner, A., Köller, U., and Semmler, W. (2007). Debt sustainability in the European Monetary Union: Theory and empirical evidence for selected countries. Oxford Economic Papers, 59(2):194218.

Gupta, S., Clements, B., Baldacci, E., and Mulas-Granados, C. (2005). Fiscal policy, expenditure composition, and growth in low-income countries. Journal of International Money and Finance, 24(3):441-463.

Heijdra, B. J. and Van Der Ploeg, F. (2002). Foundations of Modern Macroeconomics. Oxford University Press, Oxford.

Herndon, T., Ash, M., and Pollin, R. (2014). Does high public debt consistently stifle economic growth? A critique of Reinhart and Rogoff. Cambridge Journal of Economics, 38(2):257-279.

Kneller, R., Bleaney, M. F., and Gemmell, N. (1999). Fiscal policy and growth: Evidence from OECD countries. Journal of Public Economics, 74:171-190.

Lee, K., Pesaran, M. H., and Smith, R. P. (1997). Growth and convergence in a multi-country empirical stochastic Solow model. Journal of Applied Econometrics, 12(4):357-392.

Mullen, J. K. and Williams, M. (1994). Marginal tax rates and states economic growth. Regional Science and Urban Economics, 24:687-705.

Mundle, S. (1999). Fiscal policy and growth some Asian lesons for Asia. Journal of Asian Economics, $10: 15-36$.

Panizza, U. (2008). Domestic and external public debt in developing countries. United Nations Conference on Trade and Development Discussion Paper No. 188.

Panizza, U. and Presbitero, A. F. (2014). Public debt and economic growth: Is there a causal effect? Journal of Macroeconomics, 41:21-41.

Presbitero, A. F. (2012). Total public debt and growth in developing countries. The European Journal of Development Research, 24(4):606-626.

Reinhart, C. M. and Rogoff, K. S. (2010). Growth in a time of debt. American Economic Review, 100(2):573-578.

Soydan, A. and Bedir, S. (2015). External debt and economic growth: New evidence for an old debate. Journal of Business Economics and Finance, 4(3):500-522.

Turnovsky, S. J. (1996). Optimal tax, debt and expenditure policies in a growing economy. Journal of Public Economics, 60(1):21-44.

Zaman, R. and Arslan, M. (2014). The role of external debt on economic growth: Evidence from Pakistan economy. Journal of Economics and Sustainable Development, 5(24):140-147. 